\title{
Erratum to: Critical Care Toxicology - Diagnosis and Management of the Critically Poisoned Patient
}

\author{
Jeffrey Brent, Keith Burkhart, Paul Dargan, Benjamin Hatten, \\ Bruno Megarbane, Robert Palmer, and Julian White
}

(C) Springer International Publishing AG 2017

J. Brent et al. (eds.), Critical Care Toxicology, https://doi.org/10.1007/978-3-319-17900-1

FM: The affiliation details of Robert S. Hoffman for Robert J. Hoffman is updated as below in the "List of Contributors".

R.S. Hoffman

Ronald O. Perelman Department of Emergency Medicine NYU Langone Medical Center, New York, NY, USA

\section{R.J. Hoffman}

Emergency Medicine, Sidra Medical and Research Center, Doha, Qatar

Chapter 27: The author name is corrected as R.S. Hoffman.

Chapter 41: The second incorrect affiliation of R.J. Hoffman is removed.

Chapter 84: The chapter title is updated as "Phosphorus".

Chapter 143: The word "iron" in line no. 7, pg. no. 2773 is replaced by the word "deferoxamine".

The online version of the original chapters can be found at

https://doi.org/10.1007/978-3-319-17900-1_97

https://doi.org/10.1007/978-3-319-17900-1_107

https://doi.org/10.1007/978-3-319-17900-1_47

https://doi.org/10.1007/978-3-319-17900-1_170

The online version of the original book can be found at https://oi.org/10.1007/978-3-319-17900-1 